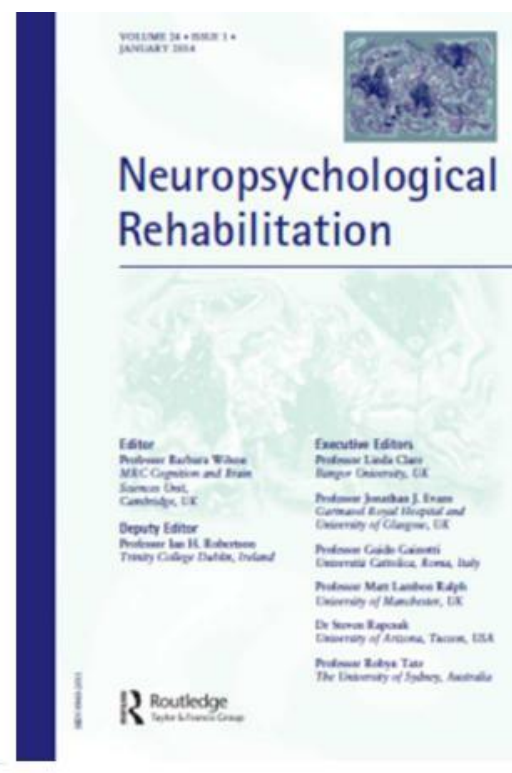

\title{
Effectiveness of cognitive rehabilitation for people with multiple sclerosis: A meta-synthesis of patient perspectives
}

\begin{tabular}{|r|l|}
\hline Journal: & Neuropsychological Rehabilitation \\
\hline Manuscript ID & NRH-OA 99.16.R1 \\
\hline Date Submitted by the Author: & n/a \\
\hline Complete List of Authors: & $\begin{array}{l}\text { Klein, Olga; University of Nottingham Faculty of Medicine and } \\
\text { Health Sciences, School of Health Sciences } \\
\text { Drummond, Avril ; University of Nottingham Faculty of Medicine and } \\
\text { Health Sciences, School of Health Sciences } \\
\text { Mhizha-Murira, Jacqueline R.; University of Nottingham Faculty of } \\
\text { Medicine and Health Sciences, School of Health Sciences } \\
\text { Mansford, Laura; University of Nottingham Faculty of Medicine and Health } \\
\text { Sciences, School of Health Sciences } \\
\text { dasNair, Roshan; University of Nottingham Faculty of Medicine and Health } \\
\text { Sciences, Division of Rehabilitation \& Ageing }\end{array}$ \\
\hline Keywords: & $\begin{array}{l}\text { cognitive rehabilitation, Multiple Sclerosis, effectiveness, } \\
\text { patient perspectives, meta-synthesis }\end{array}$ \\
\hline Word count of revised version: 7515 & \\
\hline
\end{tabular}




\section{Effectiveness of cognitive rehabilitation for people with multiple sclerosis: A meta-synthesis of patient perspectives}

Olga Klein ${ }^{1}$, Avril Drummond ${ }^{1}$, Jacqueline R. Mhizha-Murira ${ }^{1}$, Laura Mansford ${ }^{1}$, and Roshan dasNair ${ }^{2}$

'School of Health Sciences, University of Nottingham, UK

2Division of Psychiatry \& Applied Psychology, School of Medicine, University of Nottingham, UK; orcid.org/0000-0001-8143-7893

Correspondence should be addressed to Roshan dasNair, Institute of Mental Health, Jubilee Campus, Wollaton Road, Nottingham, NG8 1BB. E-mail:

Roshan.dasnair@nottingham.ac.uk

This work was supported by the MS Society PhD studentship 'Delivering cognitive rehabilitation to people with MS'; reference 8 . 


\section{Effectiveness of cognitive rehabilitation for people with multiple sclerosis: A meta-synthesis of patient perspectives}

While previous randomised controlled trials and meta-analyses offer only limited evidence for the effectiveness of cognitive rehabilitation, qualitative studies examining patient perspectives report more positive outcomes. This meta-synthesis of qualitative studies examined patient perspectives of cognitive rehabilitation for memory, attention, and executive function problems in people with multiple sclerosis. Using set eligibility criteria, we screened electronic databases, reference lists, and academic networks for relevant papers. Seven papers (195 participants) were selected. Two independent researchers conducted quality appraisals of papers. Data analysis, guided by the thematic synthesis approach, yielded six main themes. These suggested that patients benefitted from the group environment in rehabilitation. Cognitive rehabilitation facilitated the participants' reflection and awareness of their cognitive deficits, and was associated with increased knowledge and understanding of their illness. Increased strategy use was reported and associated with improvements in cognitive functioning and greater confidence and perseverance. Participants reported emotional and social improvements, and felt more optimistic. Overall, these changes had a positive impact on participants' quality of life. This synthesis of qualitative studies indicates that people with multiple sclerosis who experience cognitive deficits benefit from cognitive rehabilitation programmes. This finding must, however, be viewed in light of the limitations of this meta-synthesis. The meta-synthesis was registered in the PROSPERO database under CRD42017040148 and funded by the MS Society.

Keywords: cognitive rehabilitation; Multiple Sclerosis; effectiveness; patient perspectives; meta-synthesis 


\section{Introduction}

Multiple sclerosis (MS) is a neuro-inflammatory disease that affects approximately 100,000 people in the UK with 5,000 people newly diagnosed each year (Mackenzie, Morant, Bloomfield, MacDonald, \& O'riordan, 2014). Approximately two thirds of patients experience cognitive problems (Rao et al., 1993; Amato, Zipoli, \& Portaccio, 2006). These include deficits in memory, attention, and executive functions (Calabrese, 2006; Chiaravalotti \& DeLuca, 2008), which cause difficulties in engaging in rehabilitation, maintaining employment, and participating in social activities. A national survey of people with MS found that cognitive problems were perceived to be the most debilitating aspect of MS and a source of distress for those affected and their families and carers (Dorning, Luck, \& Holloway, 2012).

Cognitive rehabilitation is a structured set of therapeutic activities designed to retrain or compensate for an individual's impaired cognitive abilities (Tsaousides \& Gordon, 2009; dasNair, Martin, \& Sinclair, 2015). However, the evidence for the effectiveness of cognitive rehabilitation for people with MS is mixed. Although some randomised controlled trials (RCTs) have demonstrated its effectiveness (Carr, dasNair, Schwartz, \& Lincoln, 2014; Hildebrandt et al., 2007), findings from some systematic reviews on memory rehabilitation for people with MS (Brissart et al., 2011; dasNair, Ferguson, Stark, \& Lincoln, 2012) do not. The dasNair, Martin, and Lincoln (2016) Cochrane review found some evidence to support the effectiveness of memory rehabilitation for people with MS, but this was limited to objective measures of memory and quality of life. Qualitative studies, however, have suggested that cognitive rehabilitation may be helpful for people with MS with attention problems (Stuifbergen, Becker, Morgan, Morrison, \& Perez, 2011) and memory problems (dasNair \& Lincoln, 2013). 
The growing credibility of the 'insider' perspective of chronic illness has generated a surge of qualitative research conducted to gain further insight into patient perceptions and experiences (Thorne \& Paterson, 2000). dasNair and Lincoln (2013) argue that quantitative approaches alone may be inadequate in ascertaining the nuances of intervention outcomes, and quantitative measures may be insensitive to subtle changes and may not detect changes that are not predefined by the measures used. Furthermore, the psychometric properties of some questionnaires may not permit sophisticated statistical analyses. Thus, neuropsychological measures may not be sensitive to significant changes that people may experience as a result of the intervention (dasNair \& Lincoln, 2013). For instance, individuals may feel that they coped better due to the social support component of the intervention but, this aspect is rarely quantitatively measured and the positive outcome would, therefore, be missed. In addition, previous RCTs have largely focused on impairment level outcomes (Rosti-Otajärvi \& Hämäläinen, 2014), although the International Classification of Functioning, Disability and Health (ICF) suggests that the main aim of rehabilitation should be to reduce activity limitation and improve participation (World Health Organization, 2001). It is therefore crucial to ascertain patient views on the effectiveness of the intervention, how they experienced it, whether they noticed any changes as a result of the intervention, and to what components of the intervention they attribute any perceived changes. Qualitative findings may also allow for novel insights into contextual factors, patient preferences, and uncover possible barriers to engaging in rehabilitation. Such knowledge could be incorporated into a pragmatic approach to successful intervention delivery. A combination of different approaches to uncover aspects of the 'black box' of cognitive rehabilitation (Dingwall, 1992) is needed. 
Qualitative approaches do, however, have their limitations. The small sample sizes often found in qualitative studies limit the degree to which the findings can be generalizable to wider populations. However, qualitative researchers argue that addressing such issues is not the function of qualitative research and instead, by synthesising findings, researchers “could help inform the reader's judgement about the strength of evidence, provide useful sensitization to patient's concerns, and allow other insights not permitted by relying solely on quantitative data" (Dixon-Woods et al., 2007, p. 127).

One such method of qualitative synthesis in healthcare research is meta-synthesis. Fingfeld (2003) believes that a meta-synthesis is neither a systematic review nor a summing of research findings; it is the "bringing together and breaking down of findings, examining them, discovering the essential features, and, in some way, combining phenomena into a transformed whole" (Schreiber, Crooks, \& Stern, 1997, p.314). For Fingfeld (2003), "the goal of meta-synthesis is to produce a new and integrative interpretation of findings that is more substantive than those resulting from individual investigations" (p.894). Dixon-Woods et al. (2007) argue that qualitative meta-syntheses can inform the results of quantitative syntheses, and that qualitative research makes "one of its most valuable contributions when used simultaneously with, or after, a clinical trial to examine how a particular effect of an intervention was (or more commonly, was not) achieved" (p. 127). Therefore, with the publication of the latest Cochrane review of memory rehabilitation in people with MS (dasNair et al., 2016), it is timely to conduct a meta-synthesis of qualitative research that covers all aspects and delivery formats of memory rehabilitation.

Previous meta-syntheses of cognitive rehabilitation focused on people with stroke (Reed, Wood, Harrington, \& Paterson, 2012) and long-term neurological conditions in general (dasNair et al., 2015). The latter meta-synthesis was limited to group-based rehabilitation programmes. The present meta-synthesis of qualitative research focuses on the delivery of cognitive rehabilitation to people with MS, and gives an overview of the 
perceptions and experiences of this specific population. Research demonstrates that a diagnosis of MS is accompanied by an identity reconstruction and is experienced differently from other neurological disabilities (Barker, dasNair, Lincoln \& Hunt, 2014). Therefore, it was crucial to examine the experiences and perceptions of people with MS separately from other patient populations to increase our knowledge in this specific area.

The aim of this meta-synthesis was to amalgamate findings from qualitative studies of people with MS who had participated in all types of cognitive rehabilitation programmes, to gain a greater understanding of their perspectives on the effectiveness of the interventions.

\section{Methods}

The meta-synthesis was registered in the PROSPERO International prospective register of systematic reviews under CRD42017040148. In conducting this meta-synthesis, we took a critical realist approach. As such, this position does not question the 'truth' of the patients' perspectives, however, it does acknowledge the constructive aspects of the narrative form that was applied to generate knowledge. The meta-synthesis of qualitative research was conducted in the following five stages.

\section{Stage 1: Eligibility criteria for studies}

To access all relevant studies in the field, we included studies that involved people with MS aged 18 and above at the time of participation who experienced MS-related cognitive impairments as assessed by self-reports or by neuropsychological examination, and who participated in a cognitive rehabilitation 
programme designed to address memory, attention, or executive functioning deficits. No prior limitations on a specific form of cognitive rehabilitation (individual or group-based) were set to allow an initial exploration of the extant research literature in the field of MS. Studies with mixed diagnoses samples were included if it was possible to separate the data of the MS group from the other subgroups. We included mixed-methods studies if they had a distinct qualitative component, as demonstrated by direct words of participants or authors' paraphrasing of such data. There was no limitation on the studies' sample size due to the focus on the experience and perception of cognitive rehabilitation and, thus, each individual's experience is valid and should be included. Therefore, case studies were also included.

We excluded studies that were not empirical articles, did not include people with MS, were not based on an intervention study, did not use a qualitative method, did not focus on improving cognition (attention, memory, executive functions), were duplicate papers written on the same intervention study (in case of multiple publications, only one was chosen for the same intervention study), or did not focus on the patient perspective (i.e. focused on carers or staff). People under the age of 18 were excluded as the research literature suggests that pediatric MS may represent a distinct sub-type of MS (Patel, Bhise, \& Krupp, 2009; Waldman et al., 2014) and, therefore, different techniques of cognitive rehabilitation may be recommended.

We did not consider the quality of the studies at this stage as all relevant studies had the potential to contribute insights to this synthesis. Furthermore, the construction of hierarchies of evidence used in quantitative reviews may not be appropriate for qualitative reviews (Dixon-Woods et al., 2007). While it is still advisable to assess the quality of included studies to avoid drawing unreliable 
conclusions, it is imperative to apply appropriate criteria to assess the rigour of qualitative studies (Thomas \& Harden, 2008). The quality assessment of the included studies is discussed later.

\section{Stage 2: Systematic literature search}

A search strategy was developed for OVID that included access to three electronic databases: MEDLINE, EMBASE, and PsycINFO. The search strategy was also adapted for the EBSCO CINAHL database and alerts were set to highlight further potential studies. In summary, the key search terms of 'multiple sclerosis', 'cognitive rehabilitation' and 'qualitative method' were each expanded using synonyms, and combined using the Boolean operator AND (details of the search strategy available from the authors).

All searches were run with the following limits: English language, human, and adult. The last search was conducted in March 2016. In addition to the electronic search, other search methods such as searching reference lists of relevant Cochrane reviews and book chapters, as well as searching websites and academic networks (clinicaltrials.gov, searched 'multiple sclerosis AND cognitive rehabilitation'; researchgate, searched 'cognitive rehabilitation multiple sclerosis' and 'neuropsychological rehabilitation multiple sclerosis'; and google scholar, searched 'multiple sclerosis cognitive rehabilitation') were applied to ensure that no potentially relevant studies were missed. Lastly, all reference lists of the included studies were checked. All citations were checked independently for relevance by three researchers (OK, JMM, and LM) using a three-step process. First, all titles were reviewed for relevance. In cases where more information was needed abstracts were obtained as a second step and, lastly, if abstracts did not provide sufficient detail with respect to the inclusion criteria, full papers were accessed. In cases of disagreement regarding the inclusion or exclusion of a paper, opinion of another researcher $(\mathrm{RdN})$ was sought. 


\section{Stage 3: Data extraction}

A data extraction table was created to give an overview of the included studies. These data are presented in Table 1. The key themes are the original themes provided by the authors of each study.

[Table 1, Data extraction.]

\section{Stage 4: Quality appraisal of included studies}

To avoid drawing unreliable conclusions from overall and primary findings, we assessed the quality of the included studies using the Critical Appraisal Skills Programme tool (CASP, 2010). The CASP has been used in previous meta-syntheses (dasNair et al., 2014; Wilkinson \& dasNair, 2013) and includes questions that are relevant for qualitative research methods.

\section{Stage 5: Data analysis}

Several methods for synthesising qualitative research exist (Barnett-Page \& Thomas, 2009). For this meta-synthesis we employed thematic synthesis as developed by Thomas and Harden (2008). Thematic synthesis was deemed the most appropriate approach for two reasons. Firstly, the approach combines both meta-ethnography (Noblit \& Hare, 1988) and grounded theory (Glaser, Strauss, \& Strutzel, 1968) and both methods have been used widely in the literature. Secondly, thematic synthesis was developed in order to address questions regarding the appropriateness, acceptability, and effectiveness of health interventions, which is the main aim of this synthesis.

The synthesis was done in three stages which involved free line-by-line coding of the findings of the included studies, organizing related codes and constructing overarching descriptive themes for each group of codes, and lastly, the development and analysis of key concepts and themes (Thomas \& Harden, 2008). 


\section{Results}

From the 294 abstracts screened, we extracted data from seven papers based on data from 195 participants. The results of five papers were included in the thematic analysis as they provided direct patient quotations in their results section and results of all seven studies were used to arrive at final conclusions. The studies were from the UK, USA, Israel, and Finland. Two studies were based on the same intervention (Shevil \& Finlayson, 2009; Shevil \& Finlayson, 2010). Results of both were included, as the first study reported on the perceived effectiveness of the intervention based on focus groups and patient evaluations, and the second study reported on results of a 6-week follow up examining participants' use of the learned strategies and reasons for use or non-use. The results of the follow-up study increased our knowledge regarding the long-term effects of the intervention programme and it was therefore essential to include them in this synthesis. One study included a mixed diagnoses sample (dasNair \& Lincoln, 2013). The MS subgroup was the majority of the sample (21 out of 31 ) and results for the MS group were clearly identifiable. Studies used thematic analysis (dasNair \& Lincoln, 2013; Shevil \& Finlayson, 2009), content analysis (Stuifbergen et al., 2011), descriptive summary (Carr et al., 2014), narrative data (Shevil \& Finlayson, 2010), and comparative analyses (Lincoln, Dent, \& Harding, 2003; Mäntynen et al., 2014).

The results of the literature search are presented in Figure 1.

[Figure 1, PRISMA flow diagram showing the article screening process.]

A summary of the CASP ratings is shown in Table 2. All studies provided a clear statement of aims and used a research design and methodology that was appropriate with respect to their aims. All studies provided a detailed recruitment strategy. The data collection process of all studies sufficiently addressed the research issue. However, none of the studies discussed data saturation or sufficiency of data. All studies had enough detail with respect to the rigour of the data analysis and all but one study (Lincoln et al., 2003) mentioned ethical approval. However, no study discussed ethical concerns or commented on the researcherparticipant power relations. Despite the limitations, all 
studies were valuable in providing knowledge regarding the participants' perceived effectiveness of cognitive rehabilitation.

[Table 2, CASP quality assessment of included papers.]

Through the thematic synthesis, we identified six main analytical themes that encompassed the findings of the included studies. For three of the main themes we identified subthemes that referred to related but distinct aspects of the same analytical theme. The themes and subthemes are described below and corresponding quotations taken from the studies are provided. Table 3 shows a summary of the themes and indicates which themes have been endorsed by which studies.

[Table 3, Thematic structure and papers endorsing each theme and sub-theme.]

\section{Importance of group environment}

The group component, which was part of all the included studies, was mainly evident in three of the five studies because the two other studies focused on other aspects of the interventions. The second study by Shevil and Finlayson (2010), for instance, focused primarily on the type and frequency of strategy use post-intervention and the study by Stuifbergen and colleagues (2011) focused mainly on the home-based component of the intervention. Based on the three studies, the group environment yielded two subthemes, one relating to being grouped with people in the same situation (Social Support) and the other relating to the aspect of sharing and learning from each other (Sharing and Learning).

Sense of community.

Participants highlighted that the group environment of the cognitive rehabilitation programmes helped them feel they were not alone and that other people encountered 
the same or similar difficulties and issues. This aspect was seen as helpful and comforting by participants as they could relate to people who were in the same situation as they were.

"I think the biggest thing for me was listening to other people and realising that I'm not alone and I could laugh at a lot of things rather than becoming anxious about it." (dasNair \& Lincoln, 2013, p.540).

"Simply being with other people who talked about their experiences has shown me that it's not just me, that actually my memory is a lot better than many people's and [the programme] has taught me to get less stressed when I forget things." (Carr et al., 2014).

\section{Sharing and learning.}

The benefits of sharing experiences and learning from each other in a supportive environment were frequently mentioned:

"It's good to learn about other people's situations because maybe that will be something that you might have to deal with down the road." (Shevil \& Finlayson, 2009).

"So as a group we've all managed to come up with lots of new ideas." (dasNair \& Lincoln, 2013).

\section{Increased reflection and awareness}

This theme was evident in four of the five studies. Participants stated that the programme allowed them to reflect upon their cognitive deficits and acknowledge them as part of their condition. It also helped them to be aware of their cognitive problems in different situations.

Participants stated that the programme made them to "actively think" about cognitive changes (Shevil \& Finlayson, 2009, p. 80).

"... having that acknowledgement and permission from [researcher] to say it was all right, it can be happening because of your MS, and just having someone to acknowledge that, was like a huge weight off my shoulder. Because I felt like I was either going insane or I was maybe being a bit of a hypochondriac... but now I can deal with it [memory problem]." (dasNair \& Lincoln, 2013, p.534).

Participants stated that they were able to identify their "cognitive weaknesses and limitations" while completing the computer program (Stuifbergen et al., 2011, p.195). 


\section{Improved knowledge and understanding}

The interventions incorporated a theoretical session about the participants' neurological condition and mechanisms behind memory, attention, and/or executive functions in order to increase the participants' knowledge and understanding in this area. Although the majority of participants saw this component as being beneficial, some stated that they did not fully profit from it.

"I'm a teacher so I know what cognitive abilities are but unraveling that ball into component parts that was helpful to me... Like what exactly are executive functions? Defining those are helpful (focus group 2)." (Shevil \& Finlayson, 2009.p. 80).

"Yes - because it [programme] helps you understand how memory works and develop coping mechanisms." (Carr et al., 2014, p.557).

Shevil and Finlayson (2010) showed that participants continued to learn more about cognitive problems in MS - "Recognizing the problems is the biggest part." (p.48).

Although some participants did not always understand the need for psychoeducation (mainly because it often was a session that was at the beginning of the programme), the significance of it became evident for them only later.

"It [programme] was useful. When he [researcher] started going into it. I was like... 'Oh gosh, you know, do we really need to go that deep? Can't you just tell me how to manage it?' But as you go through the sessions, it all clicked into

place. So I think it [psychoeducation session] was needed." (dasNair \& Lincoln, 2013, p. 534-35).

However, some participants thought the level of these sessions was too high and too detailed.

“... because I think that was more technical. And my brain didn't absorb it all to be honest." (dasNair \& Lincoln, 2013, p.534). 


\section{Improved strategy use}

Participants in all studies reported an increase in their use of strategy as a result of the programme. Some also reported that they felt they could take on new challenges and tackle things they would not have necessarily engaged in before the programme. This shows a degree of transferability of the learned skills, as the participants started to apply them in different situation.

"... now that I can actually think which one [strategy] shall I use, which is the best one to use, because I've been given names as such. So it's easier for me now to pull in a particular strategy... sort of a tool from my toolbox to use which is appropriate for me for that particular task. So yeah, I'd say I'm a little more maybe organised." (dasNair \& Lincoln, 2013, p.535).

"Attending your course made me stop, think, adopt some strategies suggested and feel smug that I was already practicing some ideas that I had 'actually thought of myself!' [...]" (Carr et al., 2014, p.558).

Shevil and Finlayson's (2010) participants reported a number of strategies that they were still applying even after having attended the programme six weeks earlier:

Using flow charts to help with cognitive activities "helped to give me a starting point that I didn't have before. Helped to break big things down and give me direction." (Shevil \& Finlayson, 2010, p.48).

Transferability of skills.

Initial successes of applying the learned strategies led participants to take on challenges and problems that they would have not felt comfortable doing before the intervention. They were able to apply the learned skills to other situations and make it work for them.

"I found the program good because it did get me working on problems that I had not worked on in a long time. This reinforced my abilities to actually work on a problem normally out of my sphere. It did stimulate my working on problems that I normally don't see or work on. This reinforced my cognition abilities." (Stuifbergen et al., 2011, 195). 
“... I have started to do other things that I haven't done before, because I have got more confidence..." (dasNair \& Lincoln, 2013, p.539).

\section{Positive impact on quality of life}

The successful application of learned strategies appeared to have a positive impact on other areas of the participants' lives. These changes can be seen as an improvement of participants' quality of life. Researchers have proposed a quality of life model that includes three categories, namely, "being", "belonging", and "becoming" (Raphael, Renwick, Brown, \& Rootman, 1996). These categories refer to an individual's view of who one is, how one is connected to the environment, and whether one is able to achieve one's personal goals, hopes, and aspirations. Based on the participants' reports, four subthemes emerged: improved cognitive functioning, confidence and perseverance, emotional and social improvements, and changed perceptions.

Improved cognitive functioning.

Participants reported in all studies that their cognitive functioning improved as a result of the programme. In learning about and practicing the new strategies, participants felt that they managed tasks much better and forgot less often. Problem solving and planning appeared to be key aspects that they improved on.

[The program is] "definitely worth the effort. I do believe the program has helped me... [I] have become more mentally active in solving problems that I had not worked on before, or for a long time, and helped me with a push to become intellectually active." (Stuifbergen et al., 2011, p.195).

“... I'm a better planner... I do plan things better. I definitely do this with my lists, my Post-its and things so I... I am better organised. I'm not saying I don't forget things. I still do forget things. But I am better. Now I know I need to. And that makes a difference... it's taught me that I need to pay more attention really to what I'm doing." (dasNair \& Lincoln, 2013, p.537). 


\section{Confidence and perseverance.}

Participants reported that the programme had made them feel more confident and helped them persevere in tasks, which otherwise they would have given up on. The increase in confidence may also have played a role with respect to transferability of the effect of the programme as participants were more likely to take on challenging tasks and applied strategies to different situations.

"This course has made me feel more confidence and positive and encouraged me to employ lots of different ideas." (Carr et al., 2014, p.558).

“... I tell you, the biggest thing is confidence. Because it really was upsetting me and I really did think it was worse than probably what my memory is really. My husband can't get away with fibbing any more..." (dasNair \& Lincoln, 2013, p.538).

One participant stated that she had learned to "try, try again" if she didn't succeed initially with the computer based tasks, while another participant stated that "the program encouraged her not to give up on herself too soon.” (Stuifbergen et al., 2011, p.196).

\section{Emotional and social improvements.}

Another theme that emerged in three of the five studies is related to improvements in the participants' mood and social relationships. Participants reported that they felt better and were able to communicate more effectively with their partners, caregivers, and colleagues.

"Definitely improved [mood], certainly at home. I'm a lot, because I feel a lot more comfortable with my memory thing because I'm not having constantly to ask to remember, and I'm not forgetting things and that was the most frustrating part that I was just forgetting I had to be somewhere or go, you know..." (dasNair \& Lincoln, 2013, p.538).

Relationships with family, friends, and/or colleagues also appeared to have improved, because the programme taught the participants how to help others understand their cognitive problems.

"I don't think there is much out there about how to help your family or other loved ones or your work place people understand." (Shevil \& Finlayson, 2009, p.8081). 
"The communication with my wife was good... and because of this program we have been able to communicate about my cognitive deficiencies and I think she has a better understanding now." (Shevil \& Finlayson, 2009, p.81).

\section{Changed perceptions.}

Participants reported that the programme made them reconsider their negative perceptions regarding their experienced cognitive changes and they realized that they had to be more patient with themselves. They started seeing things from a more positive perspective, which has helped to reduce their stress levels, and be more compassionate with themselves.

"[...] that actually my memory is a lot better than many people's and [the programme] has taught me to get less stressed when I forget things". (Carr et al., 2014).

"You're sort of bred to think that you only deserve the carrot when you get the whole thing done. But now... you deserve that pat on the back when you get the pieces done, the intermediate goals. That was really important to me because I'm really hard on myself." (Shevil \& Finlayson, 2009, p.81).

\section{Suggested improvements}

Participants suggested some improvements to the intervention programmes and the following suggestions emerged from three of five studies. Participants suggested that it would be beneficial if caregivers would be incorporated into the programme for one or two sessions, as they may benefit from the provided knowledge as well.

"Have a session with spouse or caregiver so they can participate. It would make them more aware, and would help the family setting." (Shevil \& Finlayson, 2009, p.82). 
They also suggested that one session could include only caregivers, so they could exchange their experiences among themselves:

"Sometimes significant others need to hear what other significant others are going through... and then maybe at the end the two groups come together as sort of a wrap up." (Shevil \& Finlayson, 2009, p.82).

For the computer-based programme, the lack of feedback was seen as negative.

"I found the lack of positive reinforcement to be a negative aspect. I did not like having to go over the same exercises time and again from the start without getting credit for success." (Stuifbergen et al., 2011, p.194).

"[It] would be nice to have more hints or suggestions to help with the exercise. Perhaps a demonstration on correct methods of problem solving; an example could be given then [you] could go on and solve another problem on your own". (Stuifbergen et al., 2011, p.194).

\section{Discussion}

In this meta-synthesis of qualitative research, we examined the perceived effectiveness of cognitive rehabilitation to improve memory, attention, and/or executive functions in people with MS. All included studies offered a group-based intervention with one study focusing on the effectiveness of a computer-based programme and one focusing on the participants' usage of the strategies learnt six weeks earlier. The synthesis showed that cognitive rehabilitation programmes have a wider impact than can be identified by quantitative studies that primarily focus on improved cognitive functioning. A greater understanding of the patient perspective is crucial for two reasons. First of all, patient perspectives help us highlight personal and psychological areas that were perceived to be affected by the intervention programmes. Secondly, the patients' reasoning and attributions to the experienced changes are helpful in uncovering underlying mechanisms that contribute to either the effectiveness or ineffectiveness of cognitive rehabilitation. Therefore, qualitative studies examining the patient experience are helpful in uncovering the larger picture. Metasyntheses can further illuminate that picture by taking outcomes of multiple 
studies into account. This meta-synthesis allowed us to generate hypotheses about the underlying psychological mechanisms involved in the changes people with MS experience. The identified themes highlight key areas and impacts of cognitive rehabilitation programmes as perceived by people with MS and each theme is discussed further.

\section{Importance of group environment}

The group environment is an important component of cognitive rehabilitation programmes. The group setting offered a sense of community and a supportive environment that enabled learning and sharing. Previous research indicates that groupbased interventions are beneficial (Verhaeghen, Marcoen, \& Goossens, 1992) and have been shown to increase participants' self-efficacy (Hastings \& West, 2009), which plays a major role in how tasks and challenges are approached (Luszczynska, Gutiérrez-Doña, \& Schwarzer, 2005). However, the timing of when people are offered a group intervention needs to be considered carefully, in relation to how long people have had a diagnosis of MS (dasNair et al., 2015). General self-efficacy, the belief in one's ability to tackle novel tasks and cope with challenges in a broad range of situations is a crucial aspect of cognitive rehabilitation as it equips people with self-confidence (Luszczynska et al., 2005; Motl \& Snook, 2008). Among people with MS, greater self-efficacy beliefs with respect to function and control were associated with greater levels of physical activity and greater psychological well-being (Motl \& Snook, 2008). In addition, higher levels of social support were associated with lower levels of depression (Motl, McAuley, Snook \& Gliottoni, 2009). Participants reported benefitting from the group environment as it offered a sense of community and facilitated learning from and sharing experiences with other members. The exchange of experiences and positive reinforcement have been shown to play an important role in confidence building (Cicerone et al., 2000; Hastings \& West, 2009). Furthermore, the instructor's understanding, feedback, and emphasis on the participant's potential for memory change was also perceived as helpful. The results 
of this synthesis support these research findings and highlight the importance of social support and community sense with respect to people's health status.

\section{Increased reflection and awareness}

Participants reported that the intervention made them realise that their cognitive deficits were symptoms of their MS and they became more aware about their own cognitive changes. The latter outcome was especially reported by participants who were completing the home-based computer programme intervention. Going through the exercises made them aware of their weaknesses and areas where they would need to work on. The reflection and awareness of weaknesses is important as it gives participants a starting point from which they can work towards positive change. However, participants should not feel isolated when learning about these deficits, and feedback and support is often required. In line with our findings, previous research has shown that awareness and acceptance were associated with intervention effectiveness (Joosten-Weyn Banningh et al., 2010). In addition, personal adjustment counselling, which addresses medical issues such as cognitive deficits, has been shown to be helpful with respect to employment outcomes in people with MS (Chiu, Chan, Bishop, da Silva Cardoso, \& O’Neill, 2013). This research indicates that being able to reflect upon and recognise one's cognitive deficits may be a key component with respect to people's perceived intervention effectiveness.

\section{Improved knowledge and understanding}

While the majority reported that the inclusion of a theoretical session on cognitive functions was beneficial, some stated that they did not fully benefit from the session. Some participants explained that they only realised at a later point that knowing more about cognitive functions such as memory and attention was important as it helped them to visualise what was happening in their brain 
when they could or could not remember something. These different views on the

usefulness of theoretical sessions may be due to the participants' different levels of cognitive impairment and stage of MS. This may indicate that intervention effectiveness may be improved by either creating more homogenous groups with respect to individuals' cognitive abilities or by working in smaller groups and adapting the pace according to each group's abilities.

\section{Improved strategy use}

Participants reported an increase in strategy use as a result of the intervention programme. An aspect of increased strategy use was that participants reported tackling new challenges that they did not engage in before. This transfer of learned skills to other areas may play a significant role in maintaining the positive effects. Researchers rarely conduct follow-up studies over a long period of time to examine long-term effects of intervention programmes. Therefore, the follow-up study by Shevil and Finlayson (2010) sheds new insights about participants' ongoing strategy use six weeks post-intervention in people with MS. Further research incorporating longer-term follow-ups is needed to gain a deeper understanding of the degree to which learned skills are applied to other tasks and challenges, and the longevity of the effects of the intervention.

\section{Positive impact on quality of life}

Aside from improvements in cognitive functioning, participants reported positive change in other areas such as mood, relationships, confidence and perseverance, and perceptions. Although meta-analyses report no to little evidence with respect to the effectiveness of cognitive rehabilitation to improve memory function (Thomas, Thomas, Hillier, Galvin, \& Baker, 2006; dasNair et al., 2012; Rosti-Otajärvi \& Hämäläinen, 2014; dasNair et al., 2016), participant reports indicate perceived improvements in functioning. Low quality and heterogeneity of studies are often cited as limitations which weaken the level of evidence that can be inferred from 
reviews. Thus, more robust and methodologically refined studies are needed to be able to draw evidence-based conclusions.

Other areas that were positively affected include participants' mood and social relationships. Some RCTs (e.g., Carr et al., 2014; Tesar, Bandion, \& Baumhackl, 2005) have also observed improvements in mood for those who received cognitive rehabilitation. Participants reported that they felt better and were able to communicate more effectively with their partners, colleagues and/or caregivers. Initial successes of applying the learned strategies may have an effect on people's mood. In addition, greater knowledge regarding cognitive functions may also enable participants to communicate their challenges in a more effective way.

Another reported positive change was an increase in confidence and perseverance. Participants reported feeling more confident when they encountered cognitive challenges and felt better prepared to deal with them. In addition, participants who took part in the computer-based programme stated that it helped them to keep trying and not give up that easily, which is a crucial aspect with respect to their health status. Previous research studies have shown that a persistent and positive attitude in people with chronic illness was associated with better well-being (Hurt et al., 2013; de Ridder, Schreurs \& Bensing, 2000). The reported increase in confidence and perseverance may suggest a more optimistic outlook. Research with a focus on the role of optimism with respect to improvements in cognitive functioning may be worth further investigation in people with MS. Another theme that is in line with this previous research is changed perceptions. Participants reported changed perceptions with regard to their condition. Less worry and stress in face of challenges was the main impact stated by participants. Stress, similar to optimism, has been shown to play an important role with respect to an individual's health status. Especially in chronic illness, these factors have been shown to be associated with health outcomes (Brod, Rattazzi, Piras, D’Acquisto, 2014; Dragoş \& Tănăsescu, 2010). In the field of 
psychoneuroimmunology, researchers focused on the bi-directional relationship between psychological and biological processes and evidence from the past decades indicates that psychological factors play a role with respect to illness progression. This research is relevant to MS as the disease is the result of a hyper-responsive immune system. Thus, decreasing stress levels in participants by changing their perceptions of their condition is a crucial factor and may be a significant contributor to the perceived effectiveness of cognitive rehabilitation.

\section{Suggested improvements}

Finally, participants suggested improvements to cognitive rehabilitation programmes. As the effectiveness of such interventions is our primary research concern, it is crucial to consider participants' suggested changes. These improvements involved the involvement of the spouse or caregiver in at least one of the sessions, especially the theoretical session on cognitive function and how it is affected by MS. In addition, spouses and caregivers may also benefit from exchange among themselves to get new perspectives and learn from each other's experiences. With respect to computer-based programmes, participants mentioned the importance of positive reinforcement. This can easily be addressed in the programme and further contribute to improved functioning.

These findings must been seen as emerging from a review that has some limitations. First, like most meta-analyses, there are methodological issues tied to the process of combining the results of multiple studies. Combining qualitative research studies is a process that can be "conceptually demanding and subject to superficial and misrepresentative analysis" (Estabrooks, Field, \& Morse, 1994, p.508). While Gewurtz and colleagues state that such projects allow us to develop deeper and more accessible insights and should be recognised as "valid and scholarly contributions to knowledge" (2008, p.306), they acknowledge that some questions regarding the meta-synthesis approach remain to be further explored such as the impact of third-order interpretations on the representation of phenomena. To address this caveat, wherever possible, we worked with direct patient quotes to avoid a de-contextualization of the original data. 
Second, conclusions of this synthesis are tied to the quality of the included studies. Important quality markers such as reporting on sampling strategies, ethical considerations, and researchers' reflexivity on their role of data generation were not addressed in the included papers, which raises concerns about transparency and rigour. The debate regarding the quality appraisal of qualitative studies is widely discussed in the literature with researchers arguing that a standardised checklist may not be an appropriate tool to evaluate studies (Dixon-Woods et al., 2007). However, Thomas and Harden (2008) point out that quality remains an important anchor to avoid drawing unreliable conclusions. To address this caveat, we used the CASP to determine the possible impact of study quality on the findings of the meta-synthesis. The quality assessment was completed independently by two researchers (OK and JMM) and differences were then further discussed to arrive at an agreement. While quality assessment tools need to be improved, it is crucial that future studies follow key quality criteria such as transparency in sampling strategies, ethical considerations, and power relations. For the thematic synthesis, we only included studies that had direct quotations. To ensure that all valuable studies in this field were represented, we included two additional studies that included paraphrased patient perspectives. With this inclusion we are able to offer a fuller picture of the current stand of the literature. We did include two studies without direct quotations for second order analyses to ensure that all valuable studies in the field were represented.

A systematic search strategy does not guarantee that all relevant studies were found. In addition, the limit to articles published in English already opens the possibility 
of missing relevant studies published in other languages. Moreover, we rarely found negative patient evaluations of cognitive rehabilitation, which may be because there are none or because only positive outcomes were published. The synthesis is dependent on the reported findings of the included studies and therefore, we were bound to work with the quotations and results that were available to us. As we did not have access to full interview schedules, we could not re-track the whole interview or sequences of questions to gain a fuller context of the interview. In addition to the lack of transparency with respect to the interview schedule, the studies did not include a consideration of the participantresearcher relationship and no account of the researchers' reflexivity with respect to their role in the data generation process that could have increased the level of evidence.

Whilst we could identify some of the key aspects that appear to play a role in the perceived effectiveness of cognitive rehabilitation, it will require more focused research to disentangle the underlying processes that lead to the perceived improvements. As multiple mechanisms may be at play, it is a challenge to pinpoint the specific workings and further high quality research, that is mechanism-focused, is needed. Participant interviews with a specific focus on the perceived underlying mechanisms and attributions to the cognitive changes may shed further light.

Another issue involves the method of face-to-face interviews with people with cognitive impairments. A line of research investigating alternative methodological approaches to face-to-face interviews examines the advantages of e-mail interviews as this approach allows participants to reflect upon their answers as they can take the time they want and need to write them down. Previous research comparing face-to-face and email interviews shows that people with cognitive impairment feel more comfortable in writing than in producing on-the-spot responses (Egan, Chenoweth \& McAuliffe, 2006). People with MS may have issues remembering certain events and the need to give 'real-time' answers may cause distress or discomfort in participants which not only raises ethical issues but also influences the quality of the data as people may be inclined to give shorter answers to finish the interview quickly. These issues need to be considered when 
interviewing people with MS as the structure of the interview needs to accommodate people with varying degrees of cognitive impairment that can affect the ability to classify, store, integrate, and retrieve information (Egan et al., 2006). Therefore, e-mail facilitated interviews may be a good option. However, ultimately, perhaps participant preference should be the guide for type of method used. For future studies, it is crucial that difficulties in interviewing people with cognitive impairment are not seen in context of their deficits but rather in context of the limitations of the method that is being used (Booth \& Booth, 1996). Studies that only include high functioning people of a given population of interest minimise the transferability of their findings.

Despite these limitations, this meta-synthesis of qualitative research highlights the perceived benefits of cognitive rehabilitation in people with MS and offers suggestions to improve cognitive rehabilitation programmes. It helps to unpack findings from the quantitative reviews (e.g., dasNair et al., 2016), and where these differ from the findings of qualitative reviews, it forces us to interrogate these findings further. For instance, differences in subjective ratings of cognitive ability could be due to poor quantitative rating scales, but also due to sampling and reporting biases in qualitative studies. Further focused research is therefore needed to gain a deeper understanding of the underlying mechanisms related to the perceived positive changes 


\section{Conclusion}

In this meta-synthesis, we investigated how people with MS evaluate cognitive rehabilitation programmes. Participants reported benefits in cognitive function and other areas related to their quality of life. They reported improved mood and quality of their relationships, an increase in confidence and perseverance, and the programme helped them to change their perceptions of their condition. All these areas may play a significant role with respect to the perceived effectiveness of cognitive rehabilitation and such effects should not be underestimated. More research to further pinpoint the relationship between these factors in people with MS is needed. While participants' suggested improvements show that some aspects could be improved, this synthesis indicates that the majority of participants evaluated cognitive rehabilitation programmes positively.

We would suggest that the qualitative approach should be incorporated in future RCTs to access valuable patient perspectives. Given the problems with outcome measures in cognitive rehabilitation, using multiple methods to evaluate the effectiveness of cognitive rehabilitation will enable us to better understand the biopsychosocial nature of chronic illnesses such as MS.

\section{Acknowledgements}

The research was supported by a research grant ( $\mathrm{PhD}$ studentship) from the MS Society (https://www.mssociety.org.uk). 


\section{References}

Amato, M. P., Zipoli, V., \& Portaccio, E. (2006). Multiple sclerosis-related cognitive changes: a review of cross-sectional and longitudinal studies. Journal of the Neurological Sciences, 245(1), 41-46.

Barker, A. B., dasNair, R., Lincoln, N. B., Hunt, N. (2014). Social identity in people with multiple sclerosis: a meta-synthesis of qualitative research. Social Care and Neurodisability, 5(4), $256-267$.

Barnett-Page, E., \& Thomas, J. (2009). Methods for the synthesis of qualitative research: a critical review. BMC Medical Research Methodology, 9(1), 1.

Booth, T., \& Booth, W. (1996). Sounds of silence: Narrative research with inarticulate subjects. Disability and Society, 11, 55-69.

Brissart, H., Daniel, F., Morele, E., Leroy, M., Debouverie, M., \& Defer, G. L. (2011). Cognitive rehabilitation in multiple sclerosis: a review of the literature. Revue Neurologique, 167(4), 280-290.

Brod, S., Rattazzi, L., Piras, G., D’Acquisto, F. (2014). 'As above, so below' examining the interplay between emotion and the immune system. Immunology, 143(3), 311-318. doi:10.1111/imm.12341.

Calabrese, P. (2006). Neuropsychology of multiple sclerosis. Journal of Neurology, 253(1), 10-15.

Carr, S. E., das Nair, R., Schwartz, A. F., \& Lincoln, N. B. (2014). Group memory rehabilitation for people with multiple sclerosis: a feasibility randomized controlled trial. Clinical Rehabilitation, 28(6), 552-561.

Chiaravalloti, N.D., \& DeLuca, J. (2008). Cognitive impairment in multiple sclerosis. Lancet Neurology. 7, 1139-1151. 
Chiu, C. Y., Chan, F., Bishop, M., da Silva Cardoso, E., \& O’Neill, J. (2013). State vocational rehabilitation services and employment in multiple sclerosis. Multiple Sclerosis Journal, 19(12), 1655-1664.

Cicerone, K. D., Dahlberg, C., Kalmar, K., Langenbahn, D. M., Malec, J. F., Bergquist, T. F., ... \& Herzog, J. (2000). Evidence-based cognitive rehabilitation: recommendations for clinical practice. Archives of Physical Medicine and Rehabilitation, 81(12), 1596-1615.

dasNair, R., Ferguson, H., Stark, D. L., \& Lincoln, N. B. (2012). Memory rehabilitation for people with multiple sclerosis. Cochrane Database Syst Rev, 3.

dasNair, R., \& Lincoln, N. B. (2013). The effectiveness of memory rehabilitation following neurological disabilities: a qualitative inquiry of patient perspectives. Neuropsychological Rehabilitation, 23(4), 528-545.

dasNair, R., Martin, K. J., Lincoln, N. B. (2016). Memory rehabilitation for people with multiple sclerosis. Cochrane Database of Systematic Reviews, (3). doi: 10.1002/14651858.CD008754.pub3.

dasNair, R., Martin, K. J., \& Sinclair, E. J. (2015). A meta-synthesis of qualitative research on perceptions of people with long-term neurological conditions about group-based memory rehabilitation. Neuropsychological Rehabilitation, 25(4), 479-502.

de Ridder, D., Schreurs, K. and Bensing, J. (2000), The relative benefits of being optimistic: Optimism as a coping resource in multiple sclerosis and Parkinson's disease. British Journal of Health Psychology, 5: 141-155.

doi: $10.1348 / 135910700168829$ 
Dingwall, R. (1992). Don’t mind him - he's from Barcelona: Qualitative methods in health studies. In J. Daly, I. McDonald, \& E. Willis (Eds.). Researching health care: Designs, dilemmas, disciplines. London: Tavistock/Routledge.

Dixon-Woods, M., Sutton, A., Shaw, R., Miller, T., Smith, J., Young, B., ... \& Jones, D. (2007). Appraising qualitative research for inclusion in systematic reviews: a quantitative and qualitative comparison of three methods. Journal of Health Services Research \& Policy, 12(1), 42-47.

Dorning, H., Luck, G., Holloway, E. (2012). A lottery of treatment and care - MS services across the UK. Multiple Sclerosis Society.

Dragoş, D., \& Tănăsescu, M. (2010). The effect of stress on the defense systems. Journal of Medicine and Life, 3(1), 10-18.

Egan, J., Chenoweth, L. and McAuliffe, D. (2006). Email-facilitated qualitative interviews with traumatic brain injury survivors: A new and accessible method. Brain Injury, 20(12), pp.1283-1294.

Estabrooks, C. A., Field, P. A., \& Morse, J. M. (1994). Aggregating qualitative findings: An approach to theory development. Qualitative Health Research, 4, 503-511.

Fingfeld, D. (2003). Meta-synthesis: The state of the art—so far. Qualitative Health Research, 13, 893-904.

Glaser, B. G., Strauss, A. L., \& Strutzel, E. (1968). The discovery of grounded theory; strategies for qualitative research. Nursing research, 17(4), 364.

Gewurtz, R., Stergiou-Kita, M., Shaw, L., Kirsh, B., \& Rappolt, S. (2008). Qualitative meta-synthesis: Reflections on the utility and challenges in occupational therapy. Canadian Journal of Occupational Therapy, 75(5), 301-308.

Hastings, E. C., \& West, R. L. (2009). The Relative Success of a Self-Help and a Group-Based Memory Training Program for Older Adults. Psychology and Aging, 24(3), 586-594. http://doi.org/10.1037/a0016951. 
Hildebrandt, H., Lanz, M., Hahn, H. K., Hoffmann, E., Schwarze, B., Schwendemann, G., \& Kraus, J. A. (2007). Cognitive training in MS: effects and relation to brain atrophy. Restorative Neurology and Neuroscience, 25(1), 33-43.

Hurt, C. S., Burn, D. J., Hindle, J., Samuel, M., Wilson, K., \& Brown, R. G. (2013). Thinking positively about chronic illness: An exploration of optimism, illness perceptions and well-being in patients with Parkinson's disease. British Journal of Health Psychology, 19(2), 363-379. doi:10.1111/bjhp.12043.

Joosten-Weyn Banningh, L. W., Prins, J. B., Vernooij-Dassen, M. J., Wijnen, H. H., Olde Rikkert, M. G., \& Kessels, R. P. (2010). Group therapy for patients with mild cognitive impairment and their significant others: results of a waiting-list controlled trial. Gerontology, 57(5), 444-454.

Kern, S., \& Ziemssen, T. (2008). Review: Brain immune communication psychoneuroimmunology of multiple sclerosis. Multiple Sclerosis, 14(1), 6-21. doi:10.1177/1352458507079657.

Lincoln, N. B., Dent, A., \& Harding, J. (2003). Treatment of cognitive problems for people with multiple sclerosis. International Journal of Therapy \& Rehabilitation, 10(9).

Luszczynska, A., Gutiérrez-Doña, B. and Schwarzer, R. (2005). General self-efficacy in various domains of human functioning: Evidence from five countries. doi: $10.1080 / 00207590444000041$.

Mackenzie, I. S., Morant, S. V., Bloomfield, G. A., MacDonald, T. M., \& O'riordan, J. (2014). Incidence and prevalence of multiple sclerosis in the UK 1990-2010: a descriptive study in the General Practice Research Database. Journal of Neurology, Neurosurgery \& Psychiatry, 85(1), 76-84. 
Motl, R. W., McAuley, E., Snook, E. M., \& Gliottoni, R. C. (2009). Physical activity and quality of life in multiple sclerosis: intermediary roles of disability, fatigue, mood, pain, self-efficacy and social support. Psychology Health and Medicine, 14(1), 111-124.

Motl, R. W., \& Snook, E. M. (2008). Physical activity, self-efficacy, and quality of life in multiple sclerosis. Annals of behavioral medicine, 35(1), 111-115.

Noblit, G. W., \& Hare, R. D. (1988). Meta-ethnography: Synthesizing qualitative studies (Vol. 11). sage.

Patel, Y., Bhise, V., \& Krupp, L. (2009). Pediatric multiple sclerosis. Annals of Indian Academy of Neurology, 12(4), 238-245. http://doi.org/10.4103/09722327.58281 .

Rao S. M., Grafman J., DiGuilio D., Mittenberg W., Bernardin L., Leo G. J., Luchetta T., Unverzagt F. (1993). Memory dysfunction in multiple sclerosis: its relation to working memory, semantic encoding and implicit learning. Neuropsychology, 7, 364-374. doi:10.1037/0894-4105.7.3.364.

Raphael, D., Renwick, R., Brown, I., \& Rootman, I. (1996). Quality of life indicators and health: Current status and emerging conceptions. Social Indicators Research, 39(1), 65-88. doi:10.1007/bf00300833

Reed, M. C., Wood, V., Harrington, R., \& Paterson, J. (2012). Developing stroke rehabilitation and community services: a meta-synthesis of qualitative literature. Disability and Rehabilitation, 34(7), 553-563.

Rosti-Otajärvi, E. M., \& Hämäläinen, P. I. (2014). Neuropsychological rehabilitation for multiple sclerosis. Cochrane Database Syst Rev, 2. 
Schreiber, R., Crooks, D., \& Stern, P.N. (1997). Qualitative meta- synthesis; Issues and techniques. In Morse, J.M. Ed. Completing a qualitative project; details and dialogue. Thousand Oaks, CA: Sage.

Shevil, E., \& Finlayson, M. (2009). Process evaluation of a self-management cognitive program for persons with multiple sclerosis. Patient Education and Counseling, $76(1), 77-83$.

Shevil, E., \& Finlayson, M. (2010). Pilot study of a cognitive intervention program for persons with multiple sclerosis. Health Education Research, 25(1), 41-53.

Stuifbergen, A., Becker, H., Morgan, S., Morrison, J., \& Perez, F. (2011). Home-Based Computer-Assisted Cognitive Training: Feasibility and Perceptions of People with Multiple Sclerosis. International Journal of MS Care, 13(4), 189-198.

Tesar, N., Bandion, K., \& Baumhackl, U. (2005). Efficacy of a neuropsychological training programme for patients with multiple sclerosis-a randomised controlled trial. Wiener klinische Wochenschrift, 117(21-22), 747-754.

Thomas, J., \& Harden, A. (2008). Methods for the thematic synthesis of qualitative research in systematic reviews. BMC Medical Research Methodology, 8(1), 1.

Thomas, P. W., Thomas, S., Hillier, C., Galvin, K., \& Baker, R. (2006). Psychological interventions for multiple sclerosis. Cochrane Database Syst Rev, 1.

Thorne, S.E. \& Paterson, B.L. (2000). Two decades of insider research: what we know and don't know about chronic illness experience. Annual Review of Nursing Research, 18(1), pp.3-25.

Tsaousides, T., \& Gordon, W. A. (2009). Cognitive rehabilitation following traumatic brain injury: assessment to treatment. Mount Sinai Journal of Medicine: A Journal of Translational and Personalized Medicine, 76(2), 173-181.

Verhaeghen, P., Marcoen, A., \& Goossens, L. (1992). Improving memory 
performance in the aged through mnemonic training: a meta-analytic study. Psychology and Aging, 7(2), 242.

Waldman, A., Ghezzi, A., Bar-Or, A., Mikaeloff, Y., Tardieu, M., \& Banwell, B. (2014). Multiple sclerosis in children: an update on clinical diagnosis, therapeutic strategies, and research. The Lancet Neurology, 13(9), 936-948. http://doi.org/10.1016/S1474-4422(14)70093-6

World Health Organization (2001). International classification of functioning, disability and health: ICF. World Health Organization. 


\section{Appendix A}

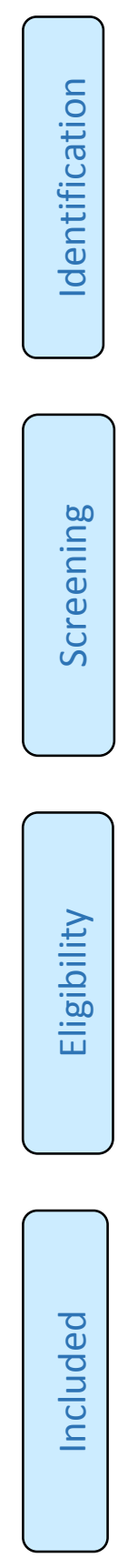
Records identified through database
searching
$(n=335)$

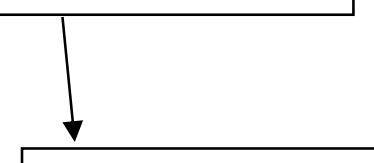

Cochrane references $(n=22)$; Research

Gate $(n=6)$; book references $(n=2)$

$(n=)$

Records after duplicates removed

$(n=294)$
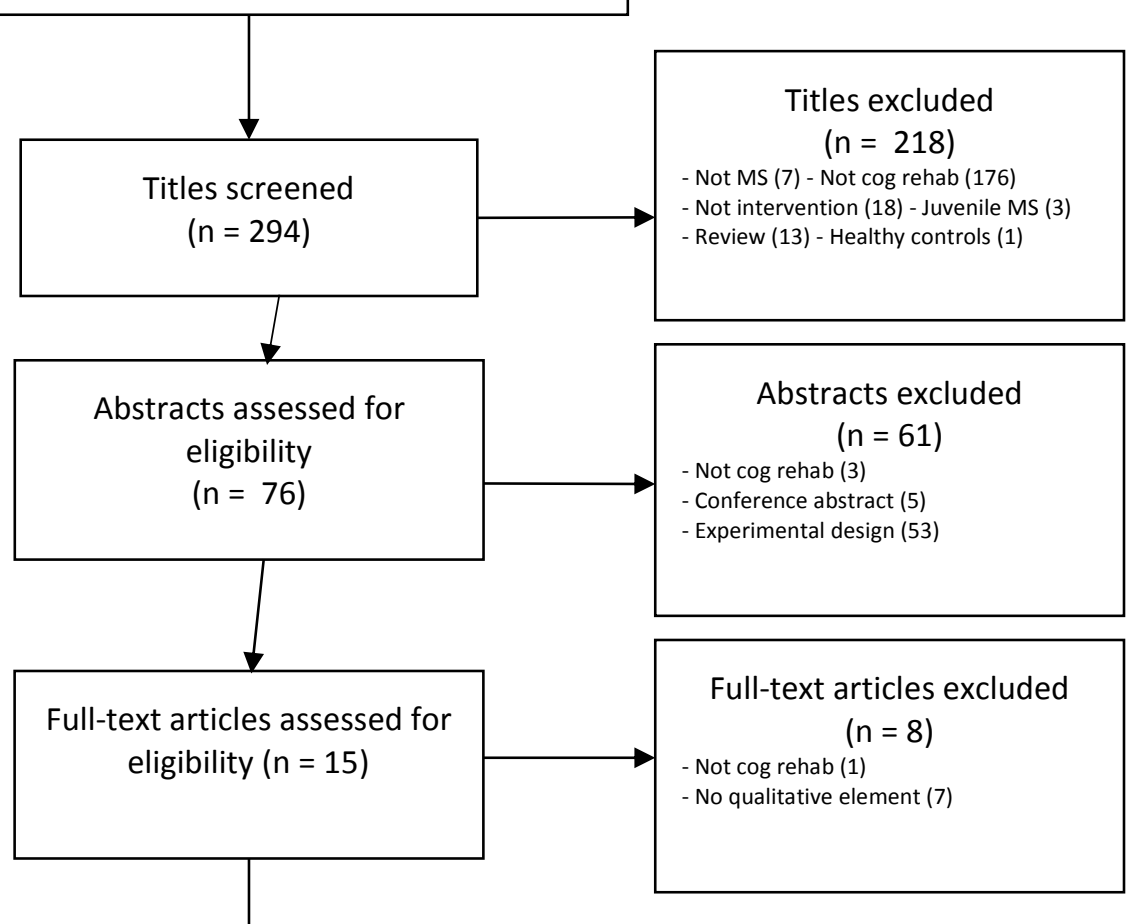

Studies included in qualitative synthesis

$(n=7)$

Figure 1. PRISMA flow diagram showing the article screening process. 


\begin{tabular}{|c|c|c|c|c|c|c|c|c|}
\hline Study & Country & Participants (N) & $\begin{array}{l}\text { Participants' } \\
\text { Age Range } \\
\text { (Mean; SD) }\end{array}$ & $\begin{array}{l}\text { Targeted } \\
\text { Cognition }\end{array}$ & Intervention strategy & Methods & Analysis & Key themes \\
\hline $\begin{array}{l}\text { Carr et al. } \\
\text { (2011) }\end{array}$ & UK & $\begin{array}{l}\text { Total 48; } 24 \\
\text { intervention } \\
\text { group (17 } \\
\text { female, } 7 \text { male); } \\
24 \text { control group } \\
\text { (16 female, } 8 \\
\text { male); } 18 \\
\text { completed the } \\
\text { intervention } \\
\text { feedback } \\
\text { questionnaire }\end{array}$ & $\begin{array}{l}34-72 \\
(54.3 ; 11.0)\end{array}$ & Memory & $\begin{array}{l}\text { Ten } 1.5 \text { hour group } \\
\text { memory rehabilitation } \\
\text { sessions }\end{array}$ & $\begin{array}{l}\text { Feedback questionnaires, } \\
\text { free text comments }\end{array}$ & Descriptive summary & $\begin{array}{l}\text { Attending had made a difference to } \\
\text { how [ppts] coped with memory } \\
\text { difficulties: } \\
\text { 1.) Being able to use specific strategies } \\
\text { 2.) Improving confidence } \\
\text { 3.) Not feeling like the only one with } \\
\text { memory difficulties; } \\
\text { 17/18 were in favour for the } \\
\text { programme }\end{array}$ \\
\hline $\begin{array}{l}\text { Das Nair \& } \\
\text { Lincoln } \\
(2013)\end{array}$ & UK & $\begin{array}{l}\text { Total } 31 ;(24 \\
\text { female, } 7 \text { male); } \\
\text { MS subgroup }= \\
\mathbf{2 1}\end{array}$ & $\begin{array}{l}18-66 \\
(45 ; 9.61)\end{array}$ & Memory & $\begin{array}{l}\text { ReMIND trial (das Nair \& } \\
\text { Lincoln 2012) Two types } \\
\text { of memory } \\
\text { rehabilitation: 1.) } \\
\text { restitution 2.) } \\
\text { compensation and } \\
\text { control group }\end{array}$ & Semi-structured interviews & $\begin{array}{l}\text { Thematic analysis (Braun \& Clarke, } \\
\text { 2006) }\end{array}$ & $\begin{array}{l}\text { 1.) Insight and awareness } \\
\text { 2.) Knowledge and skills } \\
\text { 3.) Improvements in cognitive } \\
\text { functions } \\
\text { 4.) Improvements in mood } \\
\text { 5.) Confidence, assertiveness, and } \\
\text { control } \\
\text { 6.) Altered perspective of life } \\
\text { 7.) Therapeutic effects of the group }\end{array}$ \\
\hline $\begin{array}{l}\text { Shevil \& } \\
\text { Finlayson } \\
\text { (2009) }\end{array}$ & $\begin{array}{l}\text { Israel, } \\
\text { USA }\end{array}$ & $\begin{array}{l}\text { Total } 35 ; 35 \text { ( } 26 \\
\text { female, } 9 \text { male) }\end{array}$ & $\begin{array}{l}26-70 \\
(52.4 ; 10.3)\end{array}$ & $\begin{array}{l}\text { Problem } \\
\text { solving }\end{array}$ & $\begin{array}{l}\text { Group-based and self- } \\
\text { management cognitive } \\
\text { intervention }\end{array}$ & $\begin{array}{l}\text { Focus group interviews, } \\
\text { facilitator reflection notes } \\
\text { (standard template used), } \\
\text { telephone-administered } \\
\text { program evaluations }\end{array}$ & $\begin{array}{l}\text { Descriptive statistics for program } \\
\text { evaluation; open-ended questions of } \\
\text { program evalutation, focus groups } \\
\text { interviews, and reflection notes: two- } \\
\text { phase analysis, 1.) question analysis to } \\
\text { group the data according to key issues } \\
\text { (content, structure, and recommended } \\
\text { changes) 2.) thematic analysis }\end{array}$ & $\begin{array}{l}\text { 1.) Course content } \\
\text { 2.) Format and methods of delivery } \\
\text { 3.) Recommended changes }\end{array}$ \\
\hline $\begin{array}{l}\text { Shevil \& } \\
\text { Finlayson } \\
(2010)\end{array}$ & $\begin{array}{l}\text { Israel, } \\
\text { USA }\end{array}$ & $\begin{array}{l}\text { Total } 35 ; 35 \text { ( } 26 \\
\text { female, } 9 \text { male) }\end{array}$ & $\begin{array}{l}26-70 \\
(52.4 ; 10.3)\end{array}$ & $\begin{array}{l}\text { Problem } \\
\text { solving }\end{array}$ & $\begin{array}{l}5 \text { week, group-based } \\
\text { community program } \\
\text { aimed at self- } \\
\text { management of } \\
\text { cognitive changes }\end{array}$ & $\begin{array}{l}6 \text { week follow-up, phone- } \\
\text { administered 'Cognitive } \\
\text { Strategies Questionnaire' - } \\
\text { verbally explain particular } \\
\text { strategies used/not used } \\
\text { (Understanding of ppts' } \\
\text { strategy use) }\end{array}$ & $\begin{array}{l}\text { Narrative data used to illustrate ppts' } \\
\text { perceptions regarding the use or non- } \\
\text { use of the strategy }\end{array}$ & $\begin{array}{l}\text { 1.) Help to break things down and give } \\
\text { direction } \\
\text { 2.) Tell myself what I need to do (lists } \\
\text { preferred) } \\
\text { 3.) Tell myself to think about } \\
\text { strategies } \\
\text { 4.) Nice to not feel like I'm alone } \\
\text { 5.) Helps me to think clearly and } \\
\text { concentrate on what I need to get } \\
\text { done }\end{array}$ \\
\hline
\end{tabular}




\begin{tabular}{|c|c|c|c|c|c|c|c|c|}
\hline Study & Country & Participants (N) & $\begin{array}{l}\text { Participants' } \\
\text { Age Range } \\
\text { (Mean; SD) }\end{array}$ & $\begin{array}{l}\text { Targeted } \\
\text { Cognition }\end{array}$ & Intervention strategy & Methods & Analysis & Key themes \\
\hline $\begin{array}{l}\text { Stuifbergen } \\
\text { et al. } \\
\text { (2011) }\end{array}$ & USA & $\begin{array}{l}\text { Total } 61 ; 34 \\
\text { intervention } \\
\text { group ( } 29 \\
\text { female, } 5 \text { male); } \\
27 \text { control group } \\
\text { ( } 25 \text { female, } 2 \\
\text { male) }\end{array}$ & $\begin{array}{l}\text { N/A } \\
(48.94)\end{array}$ & $\begin{array}{l}\text { Attention, } \\
\text { Memory, } \\
\text { Problem } \\
\text { solving, } \\
\text { executive } \\
\text { skills }\end{array}$ & $\begin{array}{l}\text { 1.) } 8 \text { weekly group } \\
\text { sessions of MAPSS-MS } \\
\text { 2.) home-based } \\
\text { computer-assisted } \\
\text { training (CACR) }\end{array}$ & $\begin{array}{l}\text { 1.) Data collected as part of } \\
\text { the weekly homework } \\
\text { assignments } 2 \text {.) 'End of } \\
\text { study' focus group ( } \mathrm{N}=21), 3 \\
\text { months post computer } \\
\text { training }\end{array}$ & $\begin{array}{l}\text { Descriptive statistics, content-analysis } \\
\text { (for summary of the experience using } \\
\text { the CACR program at home) }\end{array}$ & $\begin{array}{l}\text { 1.) Features of the Computer Program } \\
\text { 2.) Experiences using the Program } \\
\text { 3.) Strategy use }\end{array}$ \\
\hline
\end{tabular}

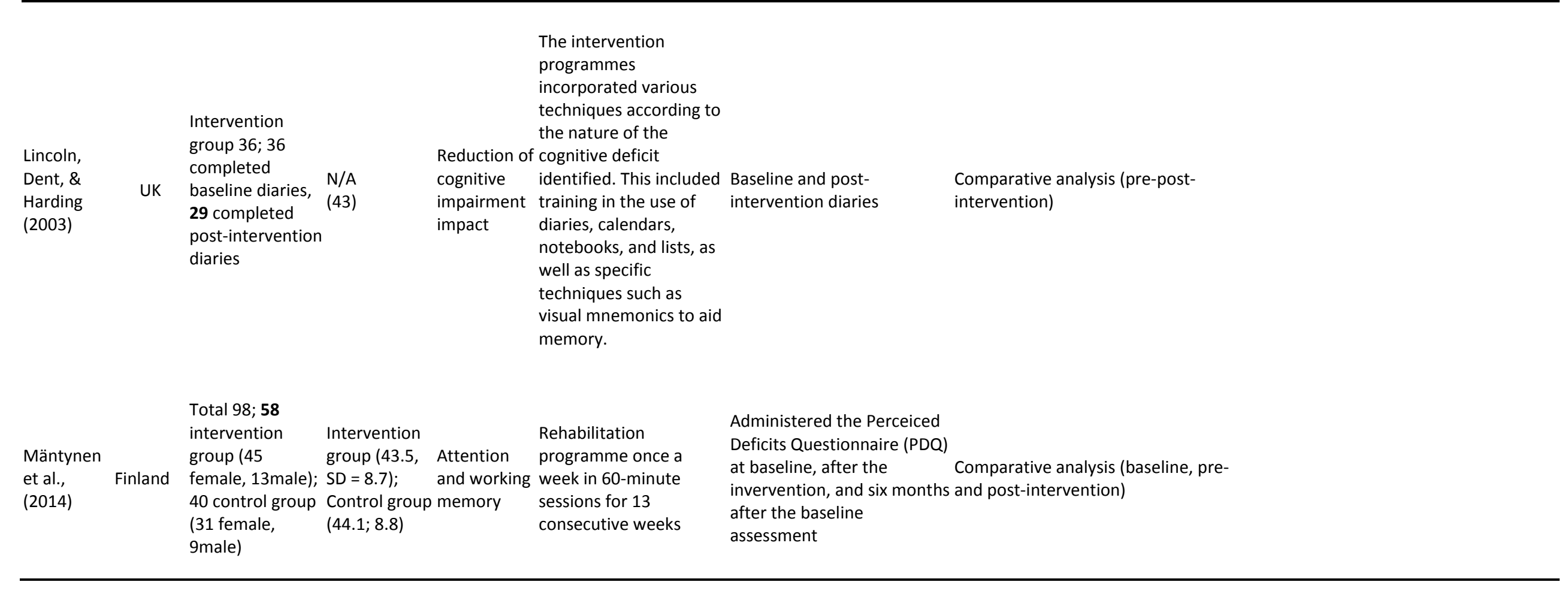

Table 1, Data extraction 


\section{Appendix C}

Table 2

CASP quality assessment of included papers

\begin{tabular}{|c|c|c|c|c|c|c|c|}
\hline Question & 1. & 2. & 3. & 4. & 5. & 6. & 7. \\
\hline Clear statement of aim? & Yes & Yes & Yes & Yes & Yes & Yes & Yes \\
\hline Appropriate qualitative methodology? & Yes & Yes & Yes & Yes & Yes & Yes & Unclear \\
\hline Research design appropriate? & Yes & Yes & Yes & Yes & Yes & Yes & Yes \\
\hline Recruitment strategy appropriate? & Yes & Yes & Yes & Yes & Yes & Yes & Yes \\
\hline $\begin{array}{l}\text { Data collection sufficiently addresses research } \\
\text { issue? }\end{array}$ & Yes & Yes & Yes & Yes & Yes & Yes & Yes \\
\hline $\begin{array}{l}\text { Relationship between researcher and participant } \\
\text { considered? }\end{array}$ & Unclear & Unclear & Unclear & Unclear & Unclear & Unclear & Unclear \\
\hline Ethical issues considered? & Yes & Yes & Yes & Yes & Yes & Unclear & Yes \\
\hline Data analysis sufficiently rigorous? & Yes & Yes & Yes & Yes & Yes & Yes & Yes \\
\hline Clear statement of findings? & Yes & Yes & Yes & Yes & Yes & Yes & Yes \\
\hline How valuable is the research? & Valuable & Valuable & Valuable & Valuable & Valuable & Valuable & Valuable \\
\hline
\end{tabular}

1. Carr et al. (2014); 2. dasNair \& Lincoln (2013); 3. Shevil \& Finlayson (2009); 4. Shevil \& Finlayson (2010); 5. Stuifbergen et al. (2011); 6. Lincoln, Dent \& Harding (2003); 7. Mäntynen et al. (2014)

Table 2, CASP quality assessment of included papers. 


\section{Appendix D}

Table 3

Thematic structure and papers endorsing each theme and sub-theme

\begin{tabular}{|c|c|c|c|c|c|}
\hline Themes and subthemes & 1. & 2. & 3. & 4. & 5. \\
\hline \multirow{3}{*}{$\begin{array}{l}\text { Group environment } \\
\text { - } \text { Sense of community } \\
\text { - } \\
\text { Sharing and learning }\end{array}$} & + & + & + & & \\
\hline & + & + & + & & \\
\hline & + & + & + & & \\
\hline \multirow{9}{*}{$\begin{array}{l}\text { Reflection \& Awareness } \\
\text { Knowledge \& Understanding } \\
\text { Improved strategy use } \\
\text { • Transferability of skills } \\
\text { Positive impact on Quality of Life } \\
\text { - Improved cognitive functioning } \\
\text { - Emotional and social improvements } \\
\text { - Confidence \& Perseverance } \\
\text { - Changed perceptions }\end{array}$} & + & + & + & & + \\
\hline & + & + & + & + & \\
\hline & + & + & + & + & + \\
\hline & + & + & + & + & + \\
\hline & + & + & + & + & + \\
\hline & + & + & + & + & + \\
\hline & & + & + & + & \\
\hline & + & + & + & & + \\
\hline & + & + & + & + & \\
\hline Suggested improvements & + & & + & & + \\
\hline
\end{tabular}

1. Carr et al. (2014); 2. dasNair \& Lincoln (2013); 3. Shevil \& Finlayson (2009); 4. Shevil \& Finlayson (2010); 5. Stuifbergen et al. (2011)

Table 3, Thematic structure and papers endorsing each theme and sub-theme. $215 \times 279 \mathrm{~mm}(150 \times 150 \mathrm{DPI})$ 


